\title{
Elevated serum osteoprotegerin levels in women: friend or foe?
}

\author{
Gisela Rodrigues da Silva Sasso ${ }^{1 *}$, Rinaldo Florencio-Silva ${ }^{2}$, Ricardo Santos Simões ${ }^{3}$, Maria Cândida Pinheiro Baracat ${ }^{4}$, \\ José Maria Soares Júnior ${ }^{5}$, Edmund Chada Baracat ${ }^{6}$ \\ ${ }^{1}$ PhD - Post-Doctoral Fellow - Department of Morphology and Genetics, Universidade Federal de São Paulo (Unifesp), São Paulo, SP, Brazil \\ ${ }^{2} \mathrm{PhD}$ - Post-Doctoral Fellow - Department of Morphology and Genetics, Unifesp, São Paulo, SP, Brazil \\ ${ }^{3}$ PhD - Physician - Department of Obstetrics and Gynecology, Faculdade de Medicina, Universidade de São Paulo (FMUSP), São Paulo, SP, Brazil \\ ${ }^{4} \mathrm{MSC}$ student - Physician - Department of Obstetrics and Gynecology, FMUSP, São Paulo, SP, Brazil \\ 5Prof. Dr. Habilitation (BR: Livre Docência) - Associate Professor in the Division of Gynecology, Department of Obstetrics and Gynecology, Faculdade de Medicina, Universidade de São Paulo (FMUSP), São Paulo, SP. Brazil \\ ${ }^{6}$ Dr., Full Professor in the Division of Gynecology, Department of Obstetrics and Gynecology, FMUSP, São Paulo, SP. Brazil
}

Study conducted at Universidade Federal de São Paulo, Escola Paulista de Medicina (Unifesp/EPM), Faculdade de Medicina da Universidade de São Paulo (FMUSP), São Paulo, SP, Brazil

Article received: $8 / 7 / 2015$ Accepted for publication: $8 / 7 / 2015$

*Correspondence: Address: Disciplina de Histologia e Biologia Estrutural, Departamento de Morfologia e Genética da Universidade Federal de São Paulo - Escola Paulista de Medicina -

UNIFESP/EPM - São Paulo (SP), Brasil Disciplina de Ginecologia, Departamento de Obstetrícia e Ginecologia da Faculdade de Medicina da Universidade de São Paulo -FMUSP - São Paulo (SP), Brasil gisela.morf@hotmail.com

http://dx.doi.org/10.1590/1806-9282.61.06.524

\section{SUMMARY}

Introduction: osteoprotegerin has emerged as a new candidate for the treatment of osteoporosis. However, high levels of osteoprotegerin have been linked to vascular calcification, an independent and well-defined risk factor for cardiovascular disease (CVD) and mortality. Thus, the action of osteoprotegerin in these situations has been questioned.

Objective: to evaluate the effect of osteoprotegerin (OPG) on the human body, especially in bone tissue and in vascular diseases.

Methods: the scientific databases consulted were PubMed-Medline and Cochrane, using keywords (MeSH terms) grouped into the following syntaxes: (Osteoprotegerin OR Osteoclastogenesis Inhibitory Factor OR Receptors, Tumor Necrosis Factor, Member 11b OR Tumor Necrosis Factor Receptor Superfamily, Member 11b OR FDCR-1 Protein OR FDCR 1 Protein OR OCIF Protein OR Follicular Dendritic Cell-Derived Receptor-1) AND (Bones AND Bone OR Bones AND Bone Tissue OR Bones OR Bone Tissue OR Cardiovascular Diseases).

Results: Osteoprotegerin is present in various organs and binds to two ligands: nuclear factor $\mathrm{kB}$ (RANKL) related to the differentiation of osteoclasts, and tumor necrosis factor related to the apoptosis-inducing ligand (TRAIL). OPG inhibits the regulation effects of nuclear factor $\mathrm{kB}$ on inflammation and on the skeletal and vascular systems, preventing the apoptosis induced by TRAIL, being related to the preservation of bone tissue.

Conclusion: a deeper knowledge of the mechanisms involved in the association between OPG serum levels, bone integrity and cardiovascular disease can provide important data for future therapeutic interventions.

Keywords: osteoprotegerin, RANK ligand, receptors, TNF-related apoptosis-inducing ligand, bone.

\section{INTRODUCTION}

Bone remodeling is a continuous physiological process that maintains skeletal integrity through bone resorption by osteoclasts, followed by bone formation by osteoblasts. This remodeling results from a time sequence that lasts six months on average. The remodeling process can be divided into four stages: 1) activation of osteoclasts (multinucleate cells responsible for bone resorption) and their precursors; 2) the resorption of old bone by the osteoclasts - which takes about three weeks; 3 ) end of bone resorption and 4) bone neoformation by osteoblasts. ${ }^{1}$
Osteoporosis is a disorder characterized by decreased bone strength and increased risk of fracture, which occurs due to an imbalance in the bone remodeling process, where bone resorption exceeds bone formation. Prevention and treatment currently available for osteoporosis include bisphosphonates and selective estrogen receptor modulators (SERMs), which are antiresorptive agents, as well as parathyroid hormone analogues such as teriparatide, which are the only anabolic agents currently approved for the treatment of osteoporosis. On the other hand, side effects and the low efficacy of the treatments 
currently available have stimulated research into the pathophysiology of osteoporosis and the study of new drugs for treatment. ${ }^{2}$

It should be noted that several researchers are looking for alternatives to improve or preserve bone mass with less side effects. ${ }^{2}$ Therefore, there is need for greater understanding of bone biology to devise new strategies and therapies to treat osteoporosis. ${ }^{3}$ Knowledge of the molecular mechanisms involved in the bone remodeling process is of paramount importance.

The onset of bone resorption is controlled by several mediators, including the receptor activator of nuclear factor-kappa B ligand (RANKL), a key cytokine for differentiation and activation of osteoclasts and their precursors. The discovery that bone marrow cells produce a natural antagonist of RANKL, known as osteoprotegerin (OPG), led to new lines of therapy. In the beginning, OPG was used as a treatment to block RANKL, and was initially successful. However, OPG antibodies seem to appear after its use, which makes its application as a treatment for osteoporosis difficult. Next, a monoclonal antibody against RANKL (Denosumab) was developed, which proved to be highly effective in the reduction of bone fractures, and is currently one of the best therapeutic options for the treatment of osteoporosis. ${ }^{3,4}$

New treatments for osteoporosis are, therefore, based on a better understanding of bone biology and the development of new, highly specific compounds, with fewer side effects. This review aims to evaluate the role of osteoprotegerin on bone tissue and other local targets for better understanding of the physiology of this protein.

\section{Methods}

The scientific databases consulted were: PubMed-Medline and Cochrane. A manual search from the references of reviews (narrative or systematic) was also performed. It included studies available in Portuguese, English, French or Spanish, whenever full texts were available. We used keywords (MeSH terms) grouped into the following syntaxes: (osteoprotegerin OR osteoclastogenesis inhibitory factor OR receptors, tumor necrosis factor, member $11 \mathrm{~b}$ OR tumor necrosis factor receptor superfamily, member 11b OR FDCR-1 protein OR FDCR 1 protein OR OCIF protein OR follicular dendritic cell-derived receptor-1) AND (bones AND bone OR bones AND bone tissue OR bones OR bone tissue OR cardiovascular diseases). Experimental studies were included, as well as case reports, case series, cohort studies and controlled clinical trials (randomized or otherwise). Studies presenting preliminary results were excluded from the evaluation.
After submitting the search strategy on the primary databases, 1,971 articles were retrieved, after which assessment of titles and abstracts resulted in thirty-nine studies considered for analysis.

\section{Osteoprotegerin (OPG)}

In 1997, Simonet et al. ${ }^{5}$ described a glycoprotein present in various organs of mice and rats (bone marrow, stomach, intestines, skin, liver, heart, lung and kidney), a member of the TNF receptor superfamily involved in bone mineral density, and named it osteoprotegerin (OPG), also known as an osteoclast inhibitory factor that regulates bone resorption. OPG is synthesized as a monomer (60 kDa), mounted as a homodimer within the cell, and then released into the blood stream, primarily as a homodimer linked by disulfide bridges. ${ }^{5}$

OPG was identified as a cytokine member of the TNF receptor superfamily that binds to two ligands, the receptor activator of nuclear factor kappa-B ligand (RANKL), a key cytokine for the differentiation of osteoclasts, and a ligand related to the induction of apoptosis (TRAIL), involved in immune surveillance. ${ }^{6}$ After binding to the first ligand, OPG inhibits the activation of osteoclasts, while the binding between OPG and TRAIL prevents apoptosis of tumor cells. Thus, as a decoding receiver for RANKL and TRAIL, OPG inhibits the regulation effects of nuclear factor $\mathrm{kB}$ on inflammation, and on the skeletal and vascular systems, preventing apoptosis induced by TRAIL.

The OPG molecule consists of three structural domains that influence its biological function. The $\mathrm{N}$-terminal portion is a cysteine rich domain important for dimerization and osteoclastogenesis, while the C-terminal portion contains death domains and a heparin binding domain. The latter domain is able to interact with different proteoglycans, including heparan sulfate and heparin. ${ }^{7}$ The connection between OPG and heparan sulfate present on the cell surface has been described in myelo$\mathrm{ma}^{8}$ cells and human monocytes. ${ }^{9}$

As mentioned, OPG is expressed highly in many organs, being produced by macrophages, the endothelium and smooth muscle cells and released into the blood stream. ${ }^{10}$ OPG is also found in the electron-bodies of platelets, which is associated with the Von Willebrand factor. ${ }^{11}$ It has also been observed that TNF- $\alpha$ and IL-1 $\beta$ increase levels of OPG, indicating that activation of endothelial cells by proinflammatory cytokines can be a possible source of circulating OPG in patients with cardiovascular disease. ${ }^{11}$ In vitro experiments have shown that after stimulation with TNF- $\alpha$, human smooth muscle cells pro- 
duce large amounts of OPG (up to 30 times more than endothelial cells), whereas insulin production decreases. ${ }^{12}$

\section{Osteoprotegerin and bone tissue}

In the mid-1990s, it was discovered that signaling via RANKL/RANK/OPG plays an important role in the regulation of bone remodeling. ${ }^{5}$ In bone tissue, osteoblasts and osteocytes produce RANKL, which in turn binds to their RANK receptor located on the outer surface of the plasma membrane of osteoclasts and their precursors, stimulating activity and osteoclast differentiation, as well as inhibiting apoptosis, increasing survival of these cells. ${ }^{13}$ Furthermore, OPG acts as a RANK competitor by binding to RANKL and preventing its interaction with RANK, thus inhibiting the formation and activity of osteoclasts ${ }^{13}$.

The central role of OPG in bone remodeling has been validated by studies on genetically modified mice with an increase in OPG expression, resulting in mice with osteopetrosis, as there is no differentiation of osteoclasts, and OPG deletion promoting an excessive increase in osteoclastogenesis and the subsequent occurrence of severe osteoporosis and fractures. ${ }^{14}$ Transgenic female rats engineered to express high OPG continuously for 1 year showed an increase in bone volume and density of the vertebrae and decreased bone resorption, with no experienced side effects. ${ }^{15}$ Thus, OPG is considered a natural antagonist of RANKL and a potent inhibitor of bone resorption, with clear protective ability against bone loss. Furthermore, several experimental studies have shown that OPG not only acts as an inhibitor of bone resorption, but its dysfunction in the RANKL/RANK/OPG pathway is related to several bone remodeling disorders, such as osteoporosis, bone loss induced by glucocorticoids, Paget's bone disease and bone metastases. ${ }^{16}$

Due to its anti-osteoclastogenesis effect, OPG has been studied and employed as a treatment for bone loss and osteoporosis. ${ }^{3}$ It has been shown that the production of OPG can be stimulated in vitro by agents used against osteoporosis, such as $17 \beta$-estradiol, ${ }^{3}$ raloxifene, ${ }^{17}$ bisphosphonates ${ }^{18}$ and mechanical stimuli. ${ }^{19}$ In vivo studies also demonstrate that parenteral administration of recombinant OPG in healthy rodents results in a marked increase in bone mass and volume, and a decrease in the number and activity of osteoclasts, in addition to completely preventing bone loss induced by ovariectomy, although without adverse effects. ${ }^{5}$ In primates, treatment with recombinant OPG promotes an increase in bone mineral density. ${ }^{20}$ Moreover, clinical studies on post-menopausal women have shown that OPG administration can reduce bone resorption and the incidence of fractures. ${ }^{18,21}$
Despite its beneficial effects against bone loss, a potential concern with the use of OPG is a possible excess accumulation of newly formed bone tissue, and little resorbed bone tissue because of its strong anti-osteoclastogenesis action. ${ }^{18}$ However, in a study in primates, relevant toxicological effects on bone were not found ${ }^{22}$ and, in human studies, only moderate asymptomatic hypocalcemia was observed two to eight days after the dose. ${ }^{23}$ Nevertheless more studies are needed to further investigate the possible side effects of treatment with OPG on the bone tissue.

\section{Osteoprotegerin and cardiovascular disease}

There is evidence toward the involvement of OPG in the pathogenesis of atherosclerosis and cardiovascular diseases (CVD), amplifying the adverse effects of inflammation and of various risk factors such as hyperlipidemia, endothelial dysfunction, diabetes mellitus and hypertension. ${ }^{24,25}$ Thus, a series of epidemiological studies have shown that increased levels of circulating OPG are associated with a significant and independent predictive value of the mortality/morbidity of cardiovascular calcification, suggesting that OPG is a possible mediator of vascular calcification. ${ }^{26}$ Arterial calcification is a part of the atherosclerotic process leading to clinical cardiovascular disease. The presence of OPG in atherosclerotic plaques has been described, and studies have shown that it is located in areas of calcification. ${ }^{27}$

High serum concentrations of OPG were correlated to the severity of peripheral arterial disease ${ }^{28}$ and heart failure, ${ }^{29}$ as well as symptomatic carotid stenosis, ${ }^{30}$ unstable angina, ${ }^{31}$ vulnerable carotid plaques, ${ }^{32}$ acute myocardial infarction and risk of death compared to controls with stable atherosclerosis. ${ }^{25}$

The relationship between OPG and CVD is supported by studies that show stimulation of OPG polymorphism, according to morphology and vascular function. ${ }^{25}$ The clinical relevance of polymorphisms is based on the fact that serum levels of OPG influence functional activity. Recently, three polymorphisms of the OPG gene have been described (T245G, T950C and G1181C), related to the serum increase of this glycoprotein, which is found more frequently in patients with atherosclerotic plaques in the carotid ${ }^{32}$ or in diabetic patients with a history of ischemic stroke. ${ }^{33}$

Using animal models, Bucay et al..$^{34}$ showed that OPG knockout mice develop spontaneous arterial calcification; therefore, OPG appears to protect against vascular calcification. Furthermore, in ApoE knockout mice (a well-known model for atherosclerosis), depletion of OPG increases the 
progression of atherosclerosis and calcification. ${ }^{35}$ Therefore, high levels of OPG seem to prevent cardiovascular events in humans. However, the protective role of OPG found in the animal model has not been observed in humans. In fact, the increase in OPG levels has been associated with the severity of cardiovascular disease.

The first association between OPG and CVD in humans was published in 2001, by Browner et al., ${ }^{36}$ who reported an association between high OPG plasma levels and increased cardiovascular mortality in a cohort study of 490 women aged over 65 . Therefore, associations between serum levels of OPG and traditional CVD risk factors have been described, including a positive correlation with smoking, fasting blood glucose, advanced age, diabetes and renal failure. ${ }^{37}$ In addition, OPG concentrations are positively correlated with coronary calcification, vascular stiffness and the presence of unstable atherosclerotic plaques. ${ }^{38,39}$

It has been reported that the increase in serum levels of OPG in patients with acute myocardial infarction is associated with decreased microcirculation after revascularization. ${ }^{40}$ In a population-based cohort study, increased OPG serum levels appear to be associated with future risk of myocardial infarction, ischemic stroke and cardiovascular mortality ${ }^{41}$ In a study of large numbers of patients with different types of cardiovascular disease, there was reported association between increased serum levels of OPG and the severity of cardiovascular disease. Additionally, increased levels of OPG were directly associated with the size of myocardial injury, estimated by magnetic resonance. ${ }^{42,43}$ Eren et al. ${ }^{44}$ suggest that OPG may play a role in the pathogenesis of parity-induced atherosclerosis, as an increased risk of cardiovascular disease and increased the thickness of the carotid intima-media layers was noted.

It should be mentioned that there is still some controversy, as Bjerre ${ }^{45}$ reports that increased levels of OPG are not directly involved with the extent of myocardial injury. The author also reports that high levels of OPG would be a biomarker for cardiovascular complications. The fact that OPG is present in platelets may be the link between increased levels of OPG and thrombosis. Thus, OPG levels may simply reflect the extent of CVD.

Although clinical results confirm that OPG is an active cytokine in a wide range of diseases (osteoporosis, arthritis, vascular calcification, bone cancer related disease), OPG plasma levels may be associated with the activity of these diseases. ${ }^{46}$

\section{Osteoprotegerin and other organs}

OPG is an essential protein in bone remodeling; however, additional data show different biological functions.
OPG may promote survival and proliferation, and facilitate cell migration by blocking apoptosis related to TNF (TRAIL), glycosaminoglycans or proteoglycans. A number of in vitro tests, pre-clinical and clinical studies also provide evidence of the involvement of OPG in the immune system. ${ }^{6}$

Studies have shown that OPG has a central role in immune response and may mediate cell survival. Yun et al. ${ }^{47}$ showed that OPG regulates B-cell maturation, as mice lacking OPG have a higher population of these cells. Furthermore, the dendritic cells of these mice have an increased capacity to stimulate $\mathrm{T}$ cells.

Indeed, OPG increases leukocyte adhesion to endothelial cells ${ }^{48}$ and stimulates the proliferation and migration of human capillary endothelial cells. ${ }^{49}$ This study suggests that OPG has a central role in immune response and may mediate cell survival. Another function relates to the fact that OPG is able to bind to TNF (TRAIL), thereby blocking apoptosis. ${ }^{50} \mathrm{Candido}^{51}$ reports increased TRAIL and OPG in the serum of patients with diabetic nephropathy, and that the pro-inflammatory cytokines and high glucose levels increase TRAIL, whereas OPG is neutralized by this action.

\section{Conclusion}

Despite osteoprotegerin being a potent inhibitor of bone loss, high serum levels of this cytokine are indicative of calcification-related vascular diseases. A deeper knowledge of the mechanisms involved in the association between OPG serum levels, bone integrity and cardiovascular disease can provide important data for future therapeutic interventions.

\section{Resumo}

Níveis séricos elevados de osteoprotegerina na mulher: aliado ou inimigo?

Introdução: a osteoprotegerina (OPG) tem surgido como uma nova candidata para o tratamento da osteoporose; no entanto, níveis elevados de OPG têm sido relacionados à calcificação vascular, um fator de risco independente e bem definido para doença cardiovascular (DCV) e mortalidade. Assim, a ação da OPG nessas situações tem sido questionada.

Objetivo: avaliar a ação da OPG no corpo humano, em especial no tecido ósseo e nas doenças vasculares.

Métodos: as bases de informação científica consultadas foram PubMed-Medline e Cochrane, utilizando-se palavras-chave (MeSH terms) agrupadas nas seguintes sinta- 
xes: (Osteoprotegerin OR Osteoclastogenesis Inhibitory Factor OR Receptors, Tumor Necrosis Factor, Member 11b OR Tumor Necrosis Factor Receptor Superfamily, Member 11b OR FDCR-1 Protein OR FDCR 1 Protein OR OCIF Protein OR Follicular Dendritic Cell-Derived Receptor-1) AND (Bones AND Bone OR Bones AND Bone Tissue OR Bones OR Bone Tissue OR Cardiovascular Diseases).

Resultados: a OPG está presente em vários órgãos e une-se a dois ligantes: o fator nuclear kB (RANKL), relacionado com a diferenciação dos osteoclastos, e o fator de necrose tumoral, relacionado ao ligante indutor de apoptose (TRAIL). Assim, a OPG inibe os efeitos da regulação do fator nuclear $\mathrm{kB}$ na inflamação e nos sistemas esquelético e vascular, prevenindo a apoptose induzida pelo TRAIL, estando relacionada com a preservação do tecido ósseo.

Conclusão: um conhecimento mais aprofundado sobre os mecanismos envolvidos na associação entre os níveis séricos da OPG, integridade óssea e doenças cardiovasculares podem proporcionar dados importantes para futuras intervenções terapêuticas.

Palavras-chave: osteoprotegerina, ligante RANK, receptores do ligante indutor de apoptose relacionado a TNF, osso e ossos.

\section{RefEREnCES}

1. Song R, Gu J, Liu X, Zhu J, Wang Q, Gao Q, et al. Inhibition of osteoclast bone resorption activity through osteoprotegerin-induced damage of the sealing zone. Int J Mol Med. 2014; 34:856-62.

2. Sharma A, Einstein AJ, Vallakati A, Arbab-Zadeh A, Walker MD, Mukherjee $\mathrm{D}$, et al. Risk of atrial fibrillation with use of oral and intravenous bisphosphonates. Am J Cardiol. 2014; 113:1815-21.

3. Bhutani G, Gupta MC. Emerging therapies for the treatment of osteoporosis. J Midlife Health. 2013; 4:147-52.

4. Miyazaki T, Tokimura F, Tanaka S. A review of denosumab for the treatment of osteoporosis. Patient Prefer Adherence. 2014; 8:463-71.

5. Simonet WS, Lacey DL, Dunstan CR, Kelley M, Chang MS, Lüthy R, et al. Osteoprotegerin: a novel secreted protein involved in the regulation of bone density. Cell. 1997; 89:309-19.

6. Baud'huin M, Duplomb L, Teletchea S, Lamoureux F, Ruiz-Velasco C, Maillasson M, et al. Osteoprotegerin: multiple partners for multiple functions. Cytokine Growth Factor Rev. 2013; 24:401-9.

7. Benslimane-Ahmim Z, Poirier F, Delomenie C, Lokajczyk A, Grelac F, GalyFauroux I, et al. Mechanistic study of the proangiogenic effect of osteoprotegerin. Angiogenesis. 2013; 16:575-93.

8. Standal T, Seidel C, Hjertner $\varnothing$, Plesner T, Sanderson RD, Waage A, et al. Osteoprotegerin is bound, internalized, and degraded by multiple myeloma cells. Blood. 2002; 100:3002-7.

9. Mosheimer BA, Kaneider NC, Feistritzer C, Djanani AM, Sturn DH, Patsch JR, et al. Syndecan-1 is involved in osteoprotegerin-induced chemotaxis in human peripheral blood monocytes. J Clin Endocrinol Metab. 2005; 90:2964-71.

10. Krämer HH, Hofbauer LC, Szalay G, Breimhorst M, Eberle T, Zieschang K, et al. Osteoprotegerin: a new biomarker for impaired bone metabolism in complex regional pain syndrome? Pain. 2014; 155:889-95.

11. Hyseni A, Roest M, Braun SL, Barendrecht AD, de Groot PG, Ndrepepa G, et al. Chronic dysfunction of the endothelium is associated with mortality in acute coronary syndrome patients. Thromb Res. 2013; 131:198-203.
12. Olesen P, Ledet T, Rasmussen LM. Arterial osteoprotegerin: increased amounts in diabetes and modifiable synthesis from vascular smooth muscle cells by insulin and TNF-alpha. Diabetologia. 2005; 48:561-8.

13. Väänänen K. Mechanism of osteoclast mediated bone resorption--rationale for the design of new therapeutics. Adv Drug Deliv Rev. 2005; 57:959-71.

14. Kong YY, Feige U, Sarosi I, Bolon B, Tafuri A, Morony S, et al. Activated T cells regulate bone loss and joint destruction in adjuvant arthritis through osteoprotegerin ligand. Nature. 1999, 402:304-9.

15. Ominsky MS, Kostenuik PJ, Cranmer P, Smith SY, Atkinson JE. The RANKL inhibitor OPG-Fc increases cortical and trabecular bone mass in young gonad-intact cynomolgus monkeys. Osteoporos Int. 2007; 18:1073-82.

16. Garnero P. New developments in biological markers of bone metabolism in osteoporosis. Bone. 2014; 66C:46-55.

17. Mencej-Bedrač S, Zupan J, Mlakar SJ, Zavratnik A, Prezelj J, Marc J. Raloxifene pharmacodynamics is influenced by genetic variants in the RANKL/RANK/ OPG system and in the Wnt signaling pathway. Drug Metabol Drug Interact. 2014; 29:111-4.

18. Tella SH, Gallagher JC. Prevention and treatment of postmenopausal osteoporosis. J Steroid Biochem Mol Biol. 2014; 142:155-70.

19. Kobayashi Y, Hashimoto F, Miyamoto H, Kanaoka K, Miyazaki-Kawashita $\mathrm{Y}$, Nakashima T, et al. Forceinduced osteoclast apoptosis in vivo is accompanied by elevation in transforming growth factor $\mathrm{b}$ and osteoprotegerin expression. J Bone Miner Res. 2000; 15:1924-34.

20. Ominsky MS, Stolina M, Li X, Corbin TJ, Asuncion FJ, Barrero M, et al. One year of transgenic overexpression of osteoprotegerin in rats suppressed bone resorption and increased vertebral bone volume, density, and strength. J Bone Miner Res. 2009; 24:1234-46.

21. Papaefthymiou MA, Bakoula C, Sarra A, Papassotiriou I, Chrousos GP, Bacopoulou F. Influence of hormonal parameters, bone mineral density and bone turnover on fracture risk in healthy male adolescents: a case control study. J Pediatr Endocrinol Metab. 2014; 27:685-92.

22. Smith BB, Cosenza ME, Mancini A, Dunstan C, Gregson R, Martin SW, et al. A toxicity profile of osteoprotegerin in the cynomolgus monkey. Int J Toxicol. 2003; 22:403-12.

23. Hamdy NA. Osteoprotegerin as a potential therapy for osteoporosis. Curr Rheumatol Rep. 2006; 8:50-4.

24. Lampropoulos CE, Papaioannou I, D’Cruz DP. Osteoporosis a risk factor for cardiovascular disease? Nat Rev Rheumatol. 2012; 8:587-98.

25. Montagnana M1, Lippi G, Danese E, Guidi GC. The role of osteoprotegerin in cardiovascular disease. Ann Med. 2013; 45:254-64.

26. Buso G, Faggin E, Pauletto P, Rattazzi M. Osteoprotegerin in cardiovascular disease: ally or enemy? Curr Pharm Des. 2014; 20:5862-9.

27. Hakimi M, Hyhlik-Dürr A, von Au A, Betz M, Demirel S, Dihlmann S, et al. The expression of glycophorin A and osteoprotegerin is locally increased in carotid atherosclerotic lesions of symptomatic compared to asymptomatic patients. Int J Mol Med. 2013; 32:331-8.

28. Ziegler S, Kudlacek S, Luger A, Minar E. Osteoprotegerin plasma concentrations correlate with severity of peripheral artery disease. Atherosclerosis. 2005; 182:175-80.

29. Ueland T, Yndestad A, Dahl CP, Gullestad L, Aukrust P. TNF revisited: osteoprotegerin and TNF-related molecules in heart failure. Curr Heart Fail Rep. 2012; 9:92-100.

30. Asanuma YF, Shimada Y, Kouzu N, Yokota K, Nakajima K, Sato K, et al. Serum osteoprotegerin concentration is associated with carotid atherosclerotic plaque in patients with rheumatoid arthritis. Mod Rheumatol. 2013; 23:269-75.

31. Aksu F, Ozçelik F, Kunduracilar H, Barutçu A, Yel M, Umit EGet al. The relation between the levels of osteoprotegerin and the degree of coronary artery disease in patients with acute coronary syndrome and stable angina pectoris. Kardiol Pol. 2014; 72(1):34-41.

32. Straface G, Biscetti F, Pitocco D, Bertoletti G, Misuraca M, Vincenzoni C, et al. Assessment of the genetic effects of polymorphisms in the osteoprotegerin gene, TNFRSF11B, on serum osteoprotegerin levels and carotid plaque vulnerability. Stroke. 2011; 42:3022-8.

33. Biscetti F, Straface G, Giovannini S, Santoliquido A, Angelini F, Santoro L, et al. Association between TNFRSF11B gene polymorphisms and history of ischemic stroke in Italian diabetic patients. Hum Genet. 2013; 132:49-55.

34. Bucay N, Sarosi I, Dunstan CR, Morony S, Tarpley J, Capparelli C, et al. Osteoprotegerin deficient mice develop early onset osteoporosis and arterial calcification. Genes Dev. 1998; 12:1260-8. 
35. Bennett BJ, Scatena M, Kirk EA, Rattazzi M, Varon RM, Averill M, et al. Osteoprotegerin inactivation accelerates advanced atherosclerotic lesion progression and calcification in older ApoE-/- mice. Arterioscler Thromb Vasc Biol. 2006; 26:2117-24.

36. Browner WS1, Lui LY, Cummings SR. Associations of serum osteoprotegerin levels with diabetes, stroke, bone density, fractures, and mortality in elderly women. J Clin Endocrinol Metab. 2001; 86:631-7.

37. Krzanowski M, Janda K, Dumnicka P, Dubiel M, Stompór M, KuśnierzCabala B, et al. Relationship between aortic pulse wave velocity, selected proinflammatory cytokines, and vascular calcification parameters in peritoneal dialysis patients. J Hypertens. 2014; 32:142-8.

38. Montecucco F, Steffens S, Mach F. The immune response is involved in atherosclerotic plaque calcification: could the RANKL/RANK/OPG system be a marker of plaque instability? Clin Dev Immunol. 2007; 2007:75805.

39. Nybo M, Rasmussen LM. The capability of plasma osteoprotegerin as a predictor of cardiovascular disease: a systematic literature review. Eur J Endocrinol. 2008; 159:603-8.

40. Løgstrup BB, Høfsten DE, Christophersen TB, Møller JE, Bjerre M, Flyvbjerg A, et al. Microvascular dysfunction is associated with plasma osteoprotegerin levels in patients with acute myocardial infarction. Coron Artery Dis. 2013; 24:487-92.

41. Mogelvang R, Haahr-Pedersen S, Bjerre M, Frystyk J, Iversen A, Galatius S, et al. Osteoprotegerin improves risk detection by traditional cardiovascular risk factors and hsCRP. Heart. 2013; 99:106-10.

42. Andersen GØ, Knudsen EC, Aukrust P, Yndestad A, Oie E, Müller C, et al. Elevated serum osteoprotegerin levels measured early after acute ST-elevation myocardial infarction predict final infarct size. Heart. 2011; 97:460-5.
43. Fuernau G, Zaehringer S, Eitel I, de Waha S, Droppa M, Desch S, et al. Osteoprotegerin in ST-elevation myocardial infarction: prognostic impact and association with markers of myocardial damage by magnetic resonance imaging. Int J Cardiol. 2013; 167:2134-9.

44. Eren MA, Vural M, Yildiz S, Cece H, Camuzcuoglu H, Toy H, et al. Association of parity with osteoprotegerin levels and atherosclerosis. Arch Gynecol Obstet. 2013; 287:1081-6.

45. Bjerre M. Osteoprotegerin (OPG) as a biomarker for diabetic cardiovascular complications. Springerplus. 2013; 2:658.

46. Bernardi S, Fabris B, Thomas M, Toffoli B, Tikellis C, Candido R, et al Osteoprotegerin increases in metabolic syndrome and promotes adipose tissue proinflammatory changes. Mol Cell Endocrinol. 2014; 394:13-2.

47. Yun TJ, Tallquist MD, Aicher A, Rafferty KL, Marshall AJ, Moon JJ, et al. Osteoprotegerin, a crucial regulator of bone metabolism, also regulates B cell development and function. J Immunol. 2001; 166:1482-91.

48. Zauli G1, Corallini F, Bossi F, Fischetti F, Durigutto P, Celeghini C, et al. Osteoprotegerin increases leukocyte adhesion to endothelial cells both in vitro and in vivo. Blood. 2007; 110:536-43.

49. Kobayashi-Sakamoto M, Isogai E, Hirose K, Chiba I. Role of alpha(v) integrin in osteoprotegerin-induced endothelial cell migration and proliferation. Microvasc Res. 2008; 4:4

50. Emery JG, McDonnell P, Burke MB, Deen KC, Lyn S, Silverman C, et al Osteoprotegerin is a receptor for the cytotoxic ligand TRAIL. J Biol Chem. $1998 ; 273: 14363-7$.

51. Candido R. The osteoprotegerin/tumor necrosis factor related apoptosisinducing ligand axis in the kidney. Curr Opin Nephrol Hypertens. 2014 23:69-74 